https://helda.helsinki.fi

\title{
Atomic layer deposited protective layers
}

\section{Leskelä, M.}

2017

Leskelä , M , Salmi , E \& Ritala , M 2017 , ' Atomic layer deposited protective layers ' ,

Materials Science Forum , vol. 879 , pp. 1086-1092 . https://doi.org/10.4028/www.scientific.net/MSF.879.1086

http://hdl.handle.net/10138/311315

https://doi.org/10.4028/www.scientific.net/MSF.879.1086

acceptedVersion

Downloaded from Helda, University of Helsinki institutional repository.

This is an electronic reprint of the original article.

This reprint may differ from the original in pagination and typographic detail.

Please cite the original version. 


\title{
Atomic Layer Deposited Protective Layers
}

\author{
Markku Leskeläa* ${ }^{*}$ Emma Salmi ${ }^{\mathrm{b}}$ and Mikko Ritala ${ }^{\mathrm{c}}$ \\ Department of Chemistry, University of Helsinki, PO. Box 55, FI-00014 Helsinki, Finland \\ aemail: markku.leskela@helsinki.fi, bemail:emma.salmi@helsinki.fi, cemail: mikko.ritala@helsinki.fi
}

Keywords: Atomic layer deposition, ALD, protective coatings, OLED, corrosion coatings.

\begin{abstract}
This paper reviews the use of Atomic Layer Deposition (ALD) in protective coatings. Because of the growth principle ALD allows the deposition of dense conformal films on substrates of different size and shape. Recently, ALD has received increasingly interest in deposition of protective coatings. In protective coatings oxides are the most common materials and especially Al, $\mathrm{Ti}$, and Ta oxides have been applied. The use of nanolaminates enables improving the protection properties. Since ALD films are pinhole-free and often thin they are used to protect against moisture, radiation, out-gassing but not often against corrosion of metals. Very good moisture barriers are obtained with thin ALD oxide layers on polymers and cardboard. This property is also very attractive in encapsulation of OLEDs. In studies of energy technology materials protection of electrodes in Li-ion batteries, fuel cells and supercapacitors by ALD has been reported and significant improvement in the stability has been achieved. Yet another area is protection of silver jewelry from tarnishing by a thin oxide layer. In traditional corrosion protection of metals ALD films have proven to be useful in tailoring of interfaces and sealing of defects in coatings made by other techniques.
\end{abstract}

\section{Introduction}

ALD is a chemical gas-phase thin film deposition technique where the film growth occurs through self-limiting and saturating chemical reactions of two or more gaseous precursors. The precursors are introduced on the substrate alternately and the reactant pulses are separated by inert gas purging [1]. The growth principle of ALD films offers several advantages from which the most important is conformality, i.e. the film follows precisely the surface morphology. The layer-bylayer growth enables easy and precise thickness control and produces dense and homogeneous films. The selection of materials deposited by ALD is wide, the most important being oxides, nitrides and metals [2]. ALD is industrially widely used in microelectronics for deposition of dielectric, conducting and barrier layers [3]. The use of ALD films in different protection applications is emerging and this technology is already used for example in passivation of Si solar cells, protection of silver jewelries and encapsulation of OLEDs. The main challenge of ALD is the low growth rate which commonly limits its use to thin films $(10-200 \mathrm{~nm})$. There are exceptions such as electroluminescent flat panel displays where the dielectric-luminescent-dielectric film stack made by ALD is $1.5 \mu \mathrm{m}$ thick [3]. Chemical protection from the environment and barrier properties against diffusion in thin film structures can be often achieved already with thin coatings but protection against mechanical wear requires often too thick films from ALD point of view because the main drawback of ALD is its slowness.

The large batch processing capability of ALD is greatly compensating for the low deposition rate and is exploited in most commercial applications [3]. Another way to increase the through put is the implementation of a roll-to-roll substrate handling scheme into the coating process. In the process called spatial atomic layer deposition (SALD) a moving substrate is alternately exposed to reactant and inert gas zones. In that way SALD replicates the conventional ALD cycle allowing continuous substrate coating and thus roll-to-roll handling and is much faster than conventional ALD [4,5]. SALD doesn't require vacuum and the process temperature is low. Due to the atmospheric pressure and low temperature the process selection in the SALD is limited to oxides of Al, Ti and $\mathrm{Zn}$ which 
have suitable precursors for the SALD conditions. Luckily these oxides are useful for many coating purposes. The material quality obtained with SALD processes is close to that achieved in batch ALD and the results for example from silicon solar passivation with SALD $\mathrm{Al}_{2} \mathrm{O}_{3}$ are promising [6]. Removal of water at low temperatures can be a problem and thus use of ozone as the oxygen source can be beneficial [7].

In the following ALD materials used in protective applications and selected application areas, such as moisture barriers, protective coatings for electrodes, and diffusion barriers are highlighted. The protection of metals is only briefly mentioned but more detailed presentation can be found from a recent review [8].

\section{ALD Materials}

$\mathrm{Al}_{2} \mathrm{O}_{3}$ is by far the most frequently used ALD material in coating and corrosion protection applications. The process employed in most cases is that using trimethyl aluminium $\left(\mathrm{Al}\left(\mathrm{CH}_{3}\right)_{3}\right.$, TMA) and water. It is considered as the most ideal ALD process and can be applied in a wide temperature range, from RT to $500{ }^{\circ} \mathrm{C}$ [9]. The as-deposited films are amorphous, which is an advantage in coating applications because grain boundaries in polycrystalline films usually serve as weak points. The films grown at low temperatures contain $\mathrm{OH}$ groups as impurities but at higher process temperatures (around $250{ }^{\circ} \mathrm{C}$ ) the composition is close to stoichiometric [10]. In ALD of oxides the surface $\mathrm{OH}$-groups play an important role and an increase of water dose can increase the growth rate [11]. Protective coatings are often deposited on polymer or metal substrates which are lacking functional groups. The nucleation of the oxide film on these substrates may be delayed. In case of polymers the traces of water remaining in the nanopores and TMA dissolved into the polymers may participate in the process and improve the nucleation $[10,12]$. The use of ozone or oxygen plasma instead of water as oxygen source enables processing of pure films at low temperatures and with improved interface properties [13]. Although the $\mathrm{ALD} \mathrm{Al}_{2} \mathrm{O}_{3}$ process is almost ideal, aluminum oxide itself is amphoteric and dissolves both in acids and bases which limits its use alone in aqueous environment.

$\mathrm{TiO}_{2}$ is the second frequently used ALD material for coating applications. The most common metal precursors for $\mathrm{TiO}_{2}$ are the chloride, different alkoxides and alkyl amides [2,14]. The benefit of the $\mathrm{TiCl}_{4}-\mathrm{H}_{2} \mathrm{O}$ process is its wide temperature range which extends from 50 to $700{ }^{\circ} \mathrm{C}[15,16]$. Metalorganic and organometallic precursors show much lower thermal stability. The films deposited at low temperature are amorphous but above $150{ }^{\circ} \mathrm{C}$ the films show anatase crystal structure and rutile is formed at higher temperature depending on the process and substrate used. Purity of the films improves with the deposition temperature. $\mathrm{TiO}_{2}$ is chemically more stable than $\mathrm{Al}_{2} \mathrm{O}_{3}$ and withstands aggressive solutions much better. However, the grain boundaries in polycrystalline films may act as routes for corrosive solutions to the surface to be protected. The use of multilayers called nanolaminates where amorphous layers interrupt the polycrystalline layers has improved the dielectric properties of ALD oxides by cutting the direct paths of electrons via grain boundaries [17]. The same principle is beneficial in protection against corrosion in solutions as proved by $\mathrm{Al}_{2} \mathrm{O}_{3} / \mathrm{TiO}_{2}$ nanolaminates $[18,19]$.

ALD tantalum oxide is commonly studied in protection applications as single layer, component of nanolaminate or mixed with other oxides $[8,18,20]$. $\mathrm{Ta}_{2} \mathrm{O}_{5}$ is chemically durable, amorphous and protects better against liquid corrosives than $\mathrm{Al}_{2} \mathrm{O}_{3}$. Several ALD processes have been developed for $\mathrm{Ta}_{2} \mathrm{O}_{5}$, the most common is using $\mathrm{Ta}$ ethoxide and water as precursors [21]. Other ALD oxides studied in protective applications are $\mathrm{SiO}_{2}, \mathrm{ZrO}_{2}, \mathrm{HfO}_{2}$, and $\mathrm{ZnO}$ [8]. From those $\mathrm{SiO}_{2}$ is amorphous whereas the others tend to crystallize at deposition temperatures normally used. $\mathrm{ZnO}$ is widely studied in ALD because of its versatile process using diethyl zinc and water (ozone) [22]. However, $\mathrm{ZnO}$ films are polycrystalline already at low deposition temperatures. 


\section{Encapsulation of Electronics}

The need of barrier films in electronics is increasing because of the use of organic materials and fast development of flexible devices. In order to be commercially successful these devices must be robust enough to survive thousands of hours in the conditions they are used. Encapsulating films are needed in solar cells (silicon, CuInGeSe/S, dye sensitized, and organic solar cells) and displays (organic LEDs and quantum dot LCD). Also OLEDs aimed for lighting application need barrier layers. Typically, organic light emitting diodes are protected by a glass substrate and a glass cover lid. ALD will be an important method in deposition of barrier films and encapsulation of devices because of the high quality conformal ALD films. Often a thin (20-200 nm) ALD layer is enough for protection. The estimated market for barrier layers is expected to more than double from 2016 (200 M\$) to 2018 (450 M\$) [23].

Many of the materials in organic electronics are sensitive to moisture and oxygen. In order to achieve device lifetimes long enough, water vapor transmission rate (WVTR) must be $10^{-6} \mathrm{~g} / \mathrm{m}^{2} /$ day and oxygen transmission rate (OTR) $<10^{-3} \mathrm{~cm}^{3} / \mathrm{m}^{2} /$ day. For organic photovoltaics the required WVTR is not as strict as for OLEDs but still at high level $\sim 10^{-5} \mathrm{~g} / \mathrm{m}^{2} /$ day. In order to fulfill these requirements the barrier coatings must be continuous, conformal, pinhole-free, and preferably transparent in the visible range and flexible [7]. Several studies have shown that ALD films fulfill or are close to fulfill these requirements. In accelerated water permeation tests performed at $60{ }^{\circ} \mathrm{C}$ and $85 \%$ relative humidity $25 \mathrm{~nm}$ of $\mathrm{Al}_{2} \mathrm{O}_{3}$ grown on polyethylene naphthalate (PEN) exhibited a WVTR level of $10^{-5} \mathrm{~g} / \mathrm{m}^{2}$ day corresponding to $6 \cdot 10^{-6} \mathrm{~g} / \mathrm{m}^{2}$ day at room temperature [24]. In an actual OLED device $180 \mathrm{~nm}$ of $\mathrm{ALD} \mathrm{Al}_{2} \mathrm{O}_{3}$ protected the device for more than $1000 \mathrm{~h}$ during accelerated WVTR testing at $85{ }^{\circ} \mathrm{C} / 85 \%$ humidity [25]. Atmospheric plasma ALD is a technology which aims to accelerate the ALD process and lower the deposition temperature. $\mathrm{Al}_{2} \mathrm{O}_{3}$ films made by atmospheric $\mathrm{O}_{2}$ plasma and trimethyl aluminum showed gas permeation barrier properties comparable to those achieved with vacuum deposited $\mathrm{Al}_{2} \mathrm{O}_{3}$ films [26].

The WVTR and OTR values required for inorganic LEDs and photovoltaics modules are significantly less strict than those for OLEDs being in the order of $10^{-2} \mathrm{~g} / \mathrm{m}^{2} /$ day and $10^{-2}$ $\mathrm{cm}^{3} / \mathrm{m}^{2} /$ day, respectively [27]. With amorphous ALD oxides theses values are clearly achievable.

\section{Coating of Food Packaging}

Aluminum and silicon oxides are commonly used barrier materials on polymers and fiber- based packaging materials. In food packaging these oxide films are replacing aluminum foil. Many methods including sputtering, evaporation and plasma-enhanced CVD can be applied for deposition of these oxides. The barrier properties of the thin film coated polymers or fiber materials depend on both the substrate and the film materials. ALD has been studied as an alternative deposition method to coat fiber materials to achieve good conformal coating and firm adherence of the film [28]. In thin film coatings preferential permeation has been seen at defects.

The barrier level required for food and pharmaceutical packaging applications is not as demanding as that needed for the protection of electronics. Barrier requirements for food products have been reported to vary between 0.01 to $100 \mathrm{~cm}^{3} / \mathrm{m}^{2} /$ day for OTR and 0.01 to $100 \mathrm{~g} / \mathrm{m}^{2} /$ day for WVTR [27]. Often narrower ranges are defined depending on the sensitivity of the material to be packaged.

Aluminum oxide has been the most studied ALD oxide for barrier applications. The challenge in the deposition is the temperature sensitivity of the packaging materials. A common material in packaging is a polymer (polyethylene) coated board and the deposition temperature on it is limited below $130{ }^{\circ} \mathrm{C}$. Hirvikorpi et al. [29] have shown that thin $(25 \mathrm{~nm})$ and highly uniform $\mathrm{Al}_{2} \mathrm{O}_{3}$ films made at relatively low temperature of 80 and $100{ }^{\circ} \mathrm{C}$ significantly enhanced the oxygen and water vapor barrier performance of various bio-based polymeric materials. WVTR and OTR values were typically between $2-12 \mathrm{~cm}^{3} / \mathrm{m}^{2} /$ day for OTR and $1-7 \mathrm{~g} / \mathrm{m}^{2} /$ day for WVTR [28]. The use of ALD is 
not limited to aluminum oxide but other oxides (titanium, silicon), nanolaminates of oxides and other materials can be employed as well $[17,18,28,30]$.

\section{Barrier Layers in Energy Technology}

Li ion battery materials is a vital research topic in ALD [31]. ALD has been used in fabrication of oxide electrodes and modification of electrode surfaces with protective layers, and solid electrolytes. The ability of ALD to produce conformal films makes it very attractive for modification of nanostructured electrodes. The reason for the degradation of the batteries is often the instability of the electrode/electrolyte interface. The degradation processes are pronounced within nanostructured electrodes and therefore their coating can be especially useful. Thin $\mathrm{Al}_{2} \mathrm{O}_{3}$ films have been grown on natural graphite composite electrodes and clear protecting behavior has been seen. When $\mathrm{LiCoO}_{2}$ powders were coated with thin conformal $\mathrm{Al}_{2} \mathrm{O}_{3}$ ALD films (3-4 $\AA$ ) they exhibited a capacity retention of $89 \%$ after 120 charge-discharge cycles. In contrast, the bare $\mathrm{LiCoO}_{2}$ powders displayed only a $45 \%$ capacity retention [32]. With nanosized $\mathrm{LiCoO}_{2}$ electrodes the difference between the $\mathrm{Al}_{2} \mathrm{O}_{3}$ coated samples and bare nanoparticles was even higher [33].

Comparison of different ALD oxide coatings $\left(\mathrm{Al}_{2} \mathrm{O}_{3}, \mathrm{TiO}_{2}, \mathrm{ZrO}_{2}\right)$ demonstrated that they have different influences on the cycling performance and the rate capability of $\mathrm{LiCoO}_{2}$ electrode. The ultra-thin $\mathrm{Al}_{2} \mathrm{O}_{3}$ layer showed great effectiveness in enhancing the cyclic performance, while $\mathrm{ZrO}_{2}$ coating layer exhibited the best effect on the rate capability of $\mathrm{LiCoO}_{2}$ electrode [34].

Lithium metal is one of the best anode materials for batteries. However, the Li surface is extremely reactive and possible reactions with solvents, contamination, and electrolyte deteriorate quickly the battery properties. Porous dendritic structures can form at the electrode/electrolyte interface which reduce the Coulombic efficiency and cause eventual failure. Ultrathin (2 nm) ALD $\mathrm{Al}_{2} \mathrm{O}_{3}$ layer can double the lifetime of Li anode before failure [35]. Kozen et al. demonstrated that a $14 \mathrm{~nm}$ thick $\mathrm{ALD} \mathrm{Al}_{2} \mathrm{O}_{3}$ layer protected the $\mathrm{Li}$ surface from corrosion due to atmosphere, sulfur, and electrolyte exposure. After 100 cycles, Li-S cells with bare Li metal anodes lost $50 \%$ of their initial capacity, while those with the ALD-protected Li metal anodes lost only $\sim 10 \%$ of their initial capacity [36].

In a traditional supercapacitor two conductive plates in a cell are coated with a porous material, most commonly activated carbon, and the cells are immersed in an electrolyte solution and the charge is stored in the electrostatic double-layer at the electrolyte-electrode interface. The high surface area electrodes in supercapacitors can be stabilized by conformal coatings of ALD oxides. As an example nano-scaled coating of $\mathrm{TiO}_{2}$ on graphene can be mentioned. The $\mathrm{TiO}_{2}$-graphene composite exhibited high capacity and no obvious degradation with respect to the electrochemical performance [37].

\section{Corrosion Protection}

Traditionally corrosion protection has meant protection of metals against liquid corrosives. ALD oxide films have also been studied in this application. Most often corrosion of steel is studied but deposits on aluminum, magnesium, copper and silver have been studied as well [8]. In brief, ALD oxide films improve the corrosion properties of steel but careful surface cleaning prior to ALD processing is necessary for good performance. $\mathrm{Al}_{2} \mathrm{O}_{3}$ is again the most studied ALD material and the properties of the $\mathrm{ALD} \mathrm{Al}_{2} \mathrm{O}_{3}$ films can be improved by making nanolaminates or mixed films with a chemically more durable oxide, e.g. $\mathrm{Ta}_{2} \mathrm{O}_{5}$ [38]. Yet, another way to apply ALD is to combine it with other techniques. ALD can be use as thin interface layer and the thicker mechanically protective film can be made by PVD. ALD can also be used to fill the pinholes present in PVD hard coating and thereby significantly improve the corrosion protection [39].

An interesting industrial application is the protective coating of silver jewels and historical artefacts with $\mathrm{ALD}$ oxide. A thin layer of $\mathrm{Al}_{2} \mathrm{O}_{3}$ or $\mathrm{Al}_{2} \mathrm{O}_{3}-\mathrm{TiO}_{2}$ protects silver from tarnishing. The 
thicknesses of the coatings are tailored to maintain the original visual appearance, and the easy removal of the coating is also desired $[40,41]$.

\section{Conclusions}

Due to the good conformality, density and defect-freeness of the ALD films the application areas of the ALD technique are constantly widening. Protective coatings is one of the application areas of ALD which shows increasing importance. A few industrial applications already exist: protecting of silver jewelries and barrier layers for silicon passivation. Many emerging areas are growing such as encapsulation of LEDs, coating of packaging materials, coating of pharmaceuticals. The development of fast ALD processes will further accelerate the usability of ALD for lowtemperature large area deposition processes.

\section{Acknowledgements}

Financial support from Academy of Finland through Finnish Centre of Excellence in ALD and EU FP7 program through project CORRAL (213996-1) is gratefully acknowledged.

\section{References}

[1] M. Leskelä, M. Ritala, Atomic layer deposition (ALD) chemistry - recent developments and future challenges. Angew. Chem. Int. Ed. 42 (2003) 5548-5554.

[2] V. Miikkulainen, M. Ritala, M. Leskelä, R.L. Puurunen, Crystallinity of inorganic films grown by atomic layer deposition: Overview and general trends. J. Appl. Phys. 113 (2013) 021301/1 101.

[3] M. Ritala, J. Niinistö, Atomic layer deposition. Chemical Vapour Deposition: Precursors, Processes and Applications, A. C. J. Jones, M. L. Hitchman, Eds. Royal Society of Chemistry, Cambridge, U.K., 2009, pp. 158-206.

[4] P. Poodt, D. C. Cameron, E. Dickey, S. M. George, V. Kuznetsov, G. N. Parsons, F. Roozeboom, G. Sundaram, A. Vermeer, Spatial atomic layer deposition: A route towards further industrialization of atomic layer deposition. J. Vac. Sci. Technol. A 30 (2012) 010802/1-12.

[5] D. Muñoz-Rojas, J. MacManus-Driscoll, Spatial atmospheric atomic layer deposition: a new laboratory and industrial tool for low-cost photovoltaics. Mater. Horiz. 1 (2014) 314-320.

[6] B. Vermang, A. Rothschild, A. Racz, J. John, J. Poortmans, R. Mertens, P. Poodt, V. Tiba, F. Roozeboom, Spatially separated atomic layer deposition of $\mathrm{Al}_{2} \mathrm{O}_{3}$, a new option for high-throughput Si solar cell passivation. Progr. Photovolt. Res. Appl. 19 (2011) 733-739.

[7] P.S. Maydannik, A. Plyushch, M. Sillanpää, D.C. Cameron, Spatial atomic layer deposition: Performance of low temperature $\mathrm{H}_{2} \mathrm{O}$ and $\mathrm{O}_{3}$ oxidant chemistry for flexible electronics encapsulation. J. Vac. Sci. Technol. A 33 (2015) 031603/1-8.

[8] E. Salmi, Atomic layer deposited coatings for corrosion protection of metals. $\mathrm{PhD}$ thesis, University of Helsinki 2015, 84 pp. E-thesis https://helda.helsinki.fi/handle/10138/156985.

[9] R.L. Puurunen, Surface chemistry of atomic layer deposition: a case study for the trimethylaluminum/water process. J. Appl. Phys. 97 (2005) 121301/1-55.

[10] M. D. Groner, F. H. Fabreguette, J. W. Elam, S. M. George, Low-temperature $\mathrm{Al}_{2} \mathrm{O}_{3}$ atomic layer deposition. Chem. Mater. 16 (2004) 639-645.

[11] R. Matero, A. Rahtu, M. Ritala, M. Leskelä, T. Sajavaara, Effect of water dose on the atomic layer deposition rate of oxide thin films. Thin Solid Films 368 (2000) 1-7. 
[12] J.D. Ferguson, A.W. Weimer, S.M. George, Atomic layer deposition of $\mathrm{Al}_{2} \mathrm{O}_{3}$ films on polyethylene particles. Chem. Mater. 16 (2004) 5602-5609.

[13] S. E. Potts, L. Schmalz, M. Fenker, B. Diaz, J. Swiatowska, V. Maurice, A. Seyeux, P. Marcus, G. Radnoczi, L. Toth, W. M. M. Kessels, Ultra-thin aluminum oxide films deposited by plasmaenhanced atomic layer deposition for corrosion protection J. Electrochem. Soc. 158 (2011) C132C138.

[14] M. Ritala, Atomic layer epitaxy growth of titanium, zirconium and hafnium dioxide thin films. $\mathrm{PhD}$ thesis. University of Helsinki 1994, $48 \mathrm{pp}$.

[15] M. Ritala, M. Leskelä, E. Nykänen, P. Soininen, L. Niinistö, ALE growth of titanium dioxide thin films. Thin Solid Films 225 (1993) 288-295.

[16] J. Aarik, A. Aidla, T. Uustare, Atomic-layer growth of $\mathrm{TiO}_{2}$-II thin films. Phil. Mag. Lett. 73 (1996) 115-119.

[17] K. Kukli, J. Ihanus, M. Ritala, Leskelä, Tailoring the dielectric properties of $\mathrm{HfO}_{2}-\mathrm{Ta}_{2} \mathrm{O}_{5}$ nanolaminates. Appl. Phys. Lett. 68 (1996) 3737-3739.

[18] R. Matero, M. Ritala, M. Leskelä, T. Salo, J. Aromaa, O. Forssen, Atomic layer deposited oxide films for corrosion protection J. Phys. IV 9 (1999) Pr8-493-499.

[19] H.-B. Wang, D.-Y. Ma, F. Ma, K.-W. Xu, Impact of ultrathin $\mathrm{Al}_{2} \mathrm{O}_{3}$ interlayer on thermal stability and leakage current properties of $\mathrm{TiO}_{2} / \mathrm{Al}_{2} \mathrm{O}_{3}$ stacking dielectrics. J. Vac. Sci. Technol. B, 30 (2012), 040601/1-6.

[20] B. Díaz, J. Swiatowska, V. Maurice, A. Seyeux, E. Härkönen, M. Ritala, S. Tervakangas, J. Kolehmainen, P. Marcus, Tantalum oxide nanocoatings prepared by atomic layer and filtered cathodic arc deposition for corrosion protection of steel: Comparative surface and electrochemical analysis. Electrochim. Acta 90 (2013) 232-245.

[21] K. Kukli, J. Aarik, A. Aidla, H. Siimon, M. Ritala. M. Leskelä, In situ study of atomic layer epitaxy growth of tantalum oxide thin films from $\mathrm{Ta}\left(\mathrm{OC}_{2} \mathrm{H}_{5}\right)_{5}$ and $\mathrm{H}_{2} \mathrm{O}$. Appl. Surf. Sci. 112 (1997) 236-242.

[22] V. Lujala, J. Skarp, M. Tammenmaa, T. Suntola, Atomic layer epitaxy growth of doped zinc oxide thin films from organometals. Appl. Surf. Sci 82/83 (1994) 34-40.

[23] Information on http://www.idtechex.com/research/reports/barrier-layers-for-flexibleelectronics-2016-2026-technologies-markets-forecasts-000455.asp

[24] P. F. Carcia, R. S. McLean, M. H. Reilly, M. D. Groner, S. M. George, Ca test of $\mathrm{Al}_{2} \mathrm{O}_{3}$ gas diffusion barriers grown by atomic layer deposition on polymers. Appl. Phys. Lett. 89 (2006) 031915/1-4.

[25] A. P. Ghosh, L. J. Gerenser, C. M. Jarman, J. E. Fornalik, Thin-film encapsulation of organic light-emitting devices. Appl. Phys. Lett. 86 (2005) 223503/1-4.

[26] L. Hoffmann, D. Theirich, T. Hasselmann, A. Räaupke, D. Schlamm, T. Riedl, Gas permeation barriers deposited by atmospheric pressure plasma enhanced atomic layer deposition. J. Vac. Sci. Technol. A 34 (2016) 01A114/1-5.

[27] C. Charton, N. Schiller, M. Fahland, A. Holländer, A. Wedel, K. Noller, Development of high barrier films on flexible polymer substrates. Thin Solid Films 502 (2006) 99-103.

[28] T. Hirvikorpi, Thin $\mathrm{Al}_{2} \mathrm{O}_{3}$ barrier coatings grown on bio-based packaging materials by atomic layer deposition. PhD thesis Aalto University 2011, VTT Publication 770, 74 pp. 
[29] T. Hirvikorpi, M. Vähä-Nissi, J. Nikkola, A. Harlin, M. Karppinen, Thin $\mathrm{Al}_{2} \mathrm{O}_{3}$ barrier coatings onto temperature-sensitive packaging materials by atomic layer deposition. Surf. Coat. Technol. 205 (2011) 5088-5092.

[30] T.O. Kääriäinen, P. Maydannik, D.C. Cameron, K. Lahtinen, P. Johansson, J. Kuusipalo, Atomic layer deposition on polymer based flexible packaging materials: Growth characteristics and diffusion barrier properties. Thin Solid Films 519 (2011) 3146-3154.

[31] O. Nilsen, V. Miikkulainen, K.B. Gandrud, E. Østreng, A. Ruud, H. Fjellvåg, Atomic layer deposition of functional films for Li-ion microbatteries. Phys Status Solidi A 211 (2014) 357-367.

[32] Y.S. Jung, A.S. Cavanagh, L.A. Riley, S-H. Kang, A.C. Dillon, M.D. Groner, S.M. George, SH. Lee, Ultrathin direct atomic layer deposition on composite electrodes for highly durable and safe Li-ion batteries. Adv. Mater. 22 (2010) 2172-2176.

[33] Y.S. Jung, A.S. Cavanagh, A.C. Dillon, M.D. Groner, S.M. George, S-H. Lee, Enhanced stability of $\mathrm{LiCoO}_{2}$ cathodes in lithium-ion batteries using surface modification by atomic layer deposition. J. Electrochem. Soc. 157 (2010) A75-A81.

[34] X. Li, J. Liu, X. Meng, Y. Tang, M.N. Banis, J. Yang, Y. Hu, R. Li, M. Cai, X. Sun, Significant impact on cathode performance of lithium-ion batteries by precisely controlled metal oxide nanocoatings via atomic layer deposition. J. Power Sources 247 (2014) 57-69.

[35] E. Kazyak, K.N. Wood, N.P. Dasgupta, Improved cycle life and stability of lithium metal anodes through ultrathin atomic layer deposition surface treatments. Chem. Mater. 27 (2015) 6457-6462.

[36] A.C. Kozen, C-F. Lin, A.J. Pearse, M. A. Schroeder, X. Han, L. Hu, S-B. Lee, G.W. Rubloff, M. Noked, Next-generation lithium metal anode engineering via atomic layer deposition. ACS Nano 9 (2015) 5884-5892.

[37] X. Sun, M. Xie, G. Wang, H. Sun, A.S. Cavanagh, J.J. Travis, S.M. George, J. Lian, Atomic layer deposition of $\mathrm{TiO}_{2}$ on graphene for supercapacitors. J. Electrochem. Soc. 159 (2012) A364A369.

[38] E. Härkönen, B. Díaz, J. Swiatowska, V. Maurice, A. Seyeux, M. Vehkamäki, T. Sajavaara, M. Fenker, P. Marcus, M. Ritala, Corrosion protection of steel with oxide nanolaminates grown by atomic layer deposition. J. Electrochem. Soc. 158 (2011) C369-C378.

[39] E. Härkönen, I. Kolev, B. Díaz, J. Swiatowska, V. Maurice, A. Seyeux, P. Marcus, M. Fenker, L. Tóth, G. Radnóczi, M. Vehkamäki, M. Ritala, Sealing of hard CrN and DLC coatings with atomic layer deposition. ACS Appl. Mater. Interf. 6 (2014) 1893-1901.

[40] M. Mäkelä, P. Soininen, S. Sneck, Protective coating of silver, U.S. Patent 8,883,258, (2014).

[41] A.E. Marquardt, E.M. Breitung, T. Drayman-Weisser, G. Gates, R. J. Phaneuf, Protecting silver cultural heritage objects with atomic layer deposited corrosion barriers. Herit. Sci. 3 (2015) 37. 